\title{
ANALYSIS OF NON-CIRCULAR MEMBERS SUBJECTED TO TWISTING LOADS: A FINITE DIFFERENCE APPROACH
}

Goteti Chaitanya R.V.R\&J.C College of Engineering, India E-mail: chaitanyagoteti16@gmail.com

Reddy Sreenivasulu R.V.R\&J.C College of Engineering, India E-mail: rslu1431@gmail.com

Submission: 03/04/2015

Revision: 19/04/2015

Accept: 24/04/2015

\section{ABSTRACT}

Many torque carrying members have circular sections such as shafts. However, there are certain structural members like automotive chasis frames, cross members and machine frames which are often subjected to twisting loads and their cross sections are non-circular. Several methods were developed to analyze such sections such as Saint Venant's semi inverse method, Prandtl's elastic membrane analogy...etc. In this paper, the second order partial differential stress function equation for non-circular torsional members is applied on a rectangular section for different $\mathrm{b} / \mathrm{h}$ (height /width of section) values and the solutions for maximum torsional shear stress are found by employing second order finite difference method. The results are compared to the results obtained from commercial finite element software (ANSYS version 10 of ANSYS Inc. which is the acronym for Analysis system) and by direct solution of the stress function equation using analytical correlations available for rectangular sections. The results obtained by different approaches are in close congruence with a percentage deviation of only 3.22. It is observed that, in implementing second order finite difference scheme, the error in estimating stress is proportional to $S^{2}$. Where " $S$ " is the grid size. 
INDEPENDENT JOURNAL OF MANAGEMENT \& PRODUCTION (IJM\&P)

http://www.ijmp.jor.br

v. 6 , n. 3, July - September 2015

ISSN: 2236-269X

DOI: 10.14807/ijmp.v6i3.323

Keywords: Non-Circular Section, Prandtl's stress function, Finite difference scheme, Grid size

\section{INTRODUCTION}

Simple torsion formulae applicable for circular sections cannot be applied directly to irregular sections as warping of sections should be considered due to uneven distribution of area around their axes of rotation. Saint-Venant (SINGH, 2013) presented stress correlations for irregular shaped members subjected to torsion by considering warping effect.

Prandtl (BORESI; SCHMIDT, 2014) developed membrane analogy for nonregular sections subjected to torsion. In this, a homogenous membrane is considered which is supported at the edges having same outline as the cross section of twisted bar and is subjected to uniform tension at the edges along with uniform lateral pressure per unit area of the membrane.

Lord Kelvin (UGURAL; FENSTER, 2003) presented hydrodynamic analogy based on similarities between torsional stress function and stream function governing motion of ideal irrotational fluids contained in a vessel having same cross section as that of the twisted bar. This analogy is especially useful for determining stress concentrations developed at sharp corners and notches in irregular shaped sections.

NewChen (1999) presented differential quadrature method. In this method a new discretization scheme is proposed for any generic problem with arbitrary domain. According to this method, a global algebraic system of equations can be developed by assembling all the discretized elements.

Turken, Kadıoğlu and Ataoğlu (2002) proposed a solution to torsion of irregular sectioned bars using boundary element method. In this method the boundary is divided into linear elements and the integral equation for torsion is reduced to a system of linear algebraic equations. Unlike in case of regular circular sections, exact numerical solutions to torsional loads are not available for irregular shaped sections.

However, Boresi and Chong (2010) presented approximate solutions to noncircular boundaries by solving the two dimensional harmonic and biharmonic stress function equations using Finite difference schemes. Strikwerda (2004) provided detailed introduction to various finite difference schemes such as Newton's forward 
DOI: 10.14807/ijmp.v6i3.323

difference formula, central difference formula...etc, for various univariate, bivariate and multi variant functions to obtain numerical solutions to partial differential equations.

Ward (1998) provided solutions to linear and second order finite difference schemes with variable coefficients. Chatopadhyaya (2013) presented and discussed the warping effects in various non circular geometries subjected to twisting loads in an elaborative manner from a series of experimental results.

In this work, a structural member of rectangular section is analyzed for different $(\mathrm{b} / \mathrm{h})$ (Section height / width) values using second order finite difference scheme and the results obtained are compared to the results obtained from (ANSYS version 10 of ANSYS Inc which is the acronym for Analysis system) finite element software and from the analytical correlations developed for non-circular sections having regular geometry. Matweb provided necessary mechanical and physical properties of chosen structural steel for modeling the member.

\section{PROBLEM DESCRIPTION AND ANALYSIS}

In the present work, a rectangular member with $\mathrm{b} / \mathrm{h}$ ratios $1.0,1.5,2.0,2.5,3.0$ is considered. The member is made of EN $24 \mathrm{~T}$ structural steel with modulus of elasticity $200 \mathrm{Gpa}$, shear modulus $76.92 \mathrm{Gpa}$ and Poisson's ratio 0.3. A torque of $2500 \mathrm{~N}-\mathrm{mm}$ is applied by constraining one end and the analysis is carried out by using Prandtl's Analytical equations, Finite difference method and Ansys.

\section{ANALYTICAL CORRELATIONS}

Recalling the Prandtl's stress function

$$
\nabla^{2} \phi=-2 G \theta
$$

Where $\nabla^{2}=\frac{\partial^{2}}{\partial x^{2}}+\frac{\partial^{2}}{\partial y^{2}}$

and $\phi$ is the stress function which is zero around the periphery of the section for equilibrium. Also, from Prandtls membrane analogy for rectangular section $T=2 \int_{-b-h}^{b} \int_{-h}^{h} \phi d x d y=G J \theta$

For the rectangular section shown in Figure 1, the stress function takes the following form 
$\phi=G \theta\left(x^{2}-h^{2}\right)+V(x, y)$

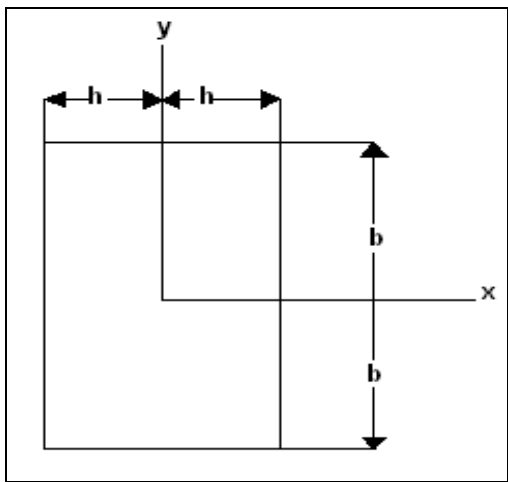

Fig 1: Rectangular Section

where

$V=\left\{\begin{array}{l}0 \text { for } x= \pm h \\ G \theta\left(x^{2}-h^{2}\right) \text { for } y= \pm b\end{array}\right.$

Where $\mathrm{V}$ is a shear stress function in $\mathrm{x}$ and $\mathrm{y}$. Employing method of separation of variables, the shear function $V$ is expressed as:

$V=f(x) g(y)$

First of equations 4 and equation 5 yields:

$$
\nabla^{2} V=g(y) f^{\square}(x)+g(y) f(x)=0
$$

Prandtl found the following closed form solutions for rectangular sections by solving equation no 6 . The solution methodology was also extended to other regular sections like equilateral triangle and ellipse by selecting appropriate equation form for $\varnothing$.

$$
\tau_{\max }=\left(\frac{T}{K_{2}(2 b)(2 h)^{2}}\right)
$$

Where T=GJ $\theta$ and $J=K_{1}(2 b)(2 h)^{3}$

Where

$$
K_{2}=\frac{K_{1}}{K}
$$




$$
K_{1}=\frac{1}{3}\left[1-\frac{192}{\pi^{5}}\left(\frac{h}{b}\right) \sum_{n=1,3,5, \ldots . .}^{\infty} \frac{1}{n^{5}} \tanh \frac{n \pi b}{2 h}\right]
$$

and

$$
K=1-\frac{8}{\pi^{2}} \sum_{n=1,3,5, \ldots . .}\left[\frac{1}{n^{2} \cosh \frac{n \pi b}{2 h}}\right]
$$

Table 1 shows the values of torsional parameters $k_{1}$ and $k_{2}$ estimated for various $b / h$ values.

Table1: Torsion Parameters for Rectangular section
\begin{tabular}{|l|l|l|l|l|l|}
\hline $\mathrm{b} / \mathrm{h}$ & 1.0 & 1.5 & 2.0 & 2.5 & 3.0 \\
\hline $\mathrm{K}_{1}$ & 0.141 & 0.196 & 0.229 & 0.249 & 0.263 \\
\hline $\mathrm{K}_{2}$ & 0.208 & 0.231 & 0.246 & 0.256 & 0.267 \\
\hline
\end{tabular}

\section{FINITE DIFFERENCE METHOD}

The section of the member under consideration for $b / h=1$ is discretized as shown in Figure 2.

Taking $b=10 \mathrm{~mm}$ and $h=10 \mathrm{~mm}$, the grid size $S$ is chosen as $10 / 4$ or $2.5 \mathrm{~mm}$. Recalling the second order finite difference equations for bi variate functions, (i,e) for functions of $x$ and $y$ variables we have:

$$
\begin{aligned}
& \frac{\partial^{2}}{\partial x^{2}}(f(x, y)) \square \frac{F(x+h, y)-2 f(x, y)+f(x-h, y)}{h^{2}} \\
& \frac{\partial^{2}}{\partial y^{2}}(f(x, y)) \square \frac{F(x+k, y)-2 f(x, y)+f(x-k, y)}{k^{2}}
\end{aligned}
$$

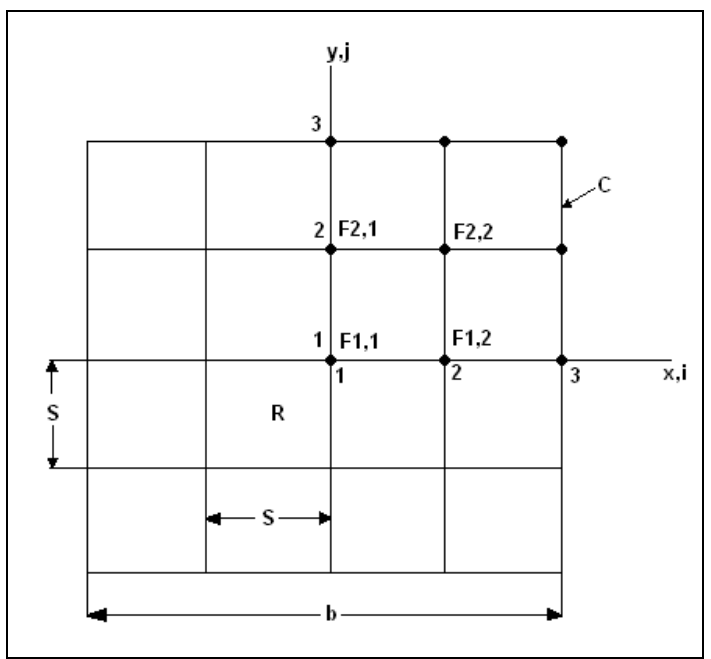

Fig 2: Finite grid for square section $(b / h=1)$ 
From Prandtl's analogy, the stress function at boundary shown in figure 2 is zero and exists throughout the region $\mathrm{R}$ shown in figure 2 except at the boundary.

Mathematically, $\quad \nabla^{2} \phi=\left(\frac{\partial^{2}}{\partial x^{2}}+\frac{\partial^{2}}{\partial y^{2}}\right) \phi=-2 G \theta$ on region defined by $\mathrm{R}$ with in the boundary. $\phi=0$ on the boundary of the member defined by $\mathrm{C}$. Due to symmetry of the section shown in figure2, only the stresses at the three node points are considered. As $\varnothing$ is function of $\mathrm{x}$ and $\mathrm{y}$, equations shown by 11 are applied to the present problem as follows.

$$
\begin{aligned}
& \frac{\partial^{2} \phi}{\partial x^{2}}=\frac{\left(\phi_{i+1, j}-2 \phi_{i, j}+\phi_{i-1, j}\right)}{S^{2}} \\
& \frac{\partial^{2} \phi}{\partial y^{2}}=\frac{\left(\phi_{i, j+1}-2 \phi_{i, j}+\phi_{i, j-1}\right)}{S^{2}}
\end{aligned}
$$

Where $\mathrm{h}=\mathrm{k}=\mathrm{S}$ and $\mathrm{i}$,j denote nodal positions in $\mathrm{x}$ and $\mathrm{y}$ directions. Therefore,

$$
\left(\nabla^{2} \phi\right) i, j \approx\left(\frac{\partial^{2} \phi}{\partial x^{2}}+\frac{\partial^{2} \phi}{\partial y^{2}}\right)=-2 G \theta \approx \frac{1}{S^{2}}\left(\phi_{i-1, j}+\phi_{i+1, j}-4 \phi_{i, j}+\phi_{i, j-1}+\phi_{i, j+1}\right)
$$

Due to symmetry only one quarter of the region $R$ shown in Figure 2 is considered for analysis. Where i, j shown in equation 12 denote the node point in region $\mathrm{R}$ of Figure 2 . Due to symmetry of node position 2 with respect to node position 1, we have $F_{1,2}=F_{2,1}$. Here, it must be noted that the function $\varnothing$ is analogous to $F$ shown in Figure 2. The following equations are deduced for nodal positions $(1,1),(1,2)$ and $(2,2)$.

$i=1, j=1 ; F_{2,1}+F_{2,1}-4 F_{1,1}+F_{2,1}+F_{2,1}=-2 G \theta S^{2}$

( $\varnothing_{0,1}$ and $\varnothing_{1,0}$ denote $F_{2,1}$ and $\varnothing_{1,1}$ denotes $F_{1,1}$ )

$i=1, j=2 ; F_{2,2}+F_{2,2}-4 F_{2,1}+F_{1,1}+0=-2 G \theta S^{2}$

( $\mathrm{j}+1$ denotes boundary $\mathrm{C}$, therefore 5 th term is zero)

$i=2, j=2 ; F_{2,1}+0-4 F_{2,2}+F_{2,1}+0=-2 G \theta S^{2}$

$\left(\mathrm{i}+1, \mathrm{j}+1\right.$ denote boundary $\mathrm{C}$, therefore, $2^{\text {nd }} \& 5^{\text {th }}$ term are zero)

Equations 13 to 15 can be expressed as shown by equations 16,17 and 18 .

$-4 F_{1,1}+4 F_{2,1}=-2 G \theta S^{2}$ 


$$
\begin{aligned}
& F_{1,1}-4 F_{2,1}+2 F_{2,2}=-2 G \theta S^{2} \\
& 2 F_{2,1}-4 F_{2,2}=-2 G \theta S^{2}
\end{aligned}
$$

Solving equations 16 to 18 we have the following solutions for stresses.

$$
\begin{aligned}
& F_{1,1}=-2.250 G \theta S^{2} \\
& F_{2,1}=1.750 G \theta S^{2} \\
& F_{2,2}=1.375 G \theta S^{2}
\end{aligned}
$$

For one quarter of region $R$, the maximum shear stress occurs at $i=3$ and $j=1$, That is at $x=b / 2, y=0$ position For the entire region $R$.

$$
\tau_{\max }=\frac{\partial \phi}{\partial x}
$$

Using fourth order backward difference formula tmax may be approximated as:

$$
\left(\frac{\partial \phi}{\partial x}\right)_{i, j}=\frac{1}{24 S}\left(6 F_{i-4, j}-32 F_{i-3, j}+72 F_{i-2, j}-96 F_{i-1, j}+50 F_{i . j}\right)
$$

For $\mathrm{i}=3, \mathrm{j}=1$ equation 20 becomes:

$$
\tau_{\text {max }}=-\left(\frac{\partial \phi}{\partial x}\right)_{3,1}=\frac{1}{24 S}\left(0-32 F_{2,1}+72 F_{1,1}-96 F_{2,1}+0\right)
$$

From equations 19 and $20 \quad \operatorname{tmax}=2.583 \mathrm{G} \theta \mathrm{S}=0.646 \mathrm{G} \theta \mathrm{b}$

\section{FINITE ELEMENT METHOD}

Ansys 10 version of ANSYS Inc. is used to model and analyze the present problem. The section is modeled using SOLID 45 brick elements. The entire section is meshed with uniform map mesh of initial element size 10. Torque of $2500 \mathrm{~N}-\mathrm{mm}$ is applied to the model using a pilot node modeled outside the model. Figure 3 shows the finite element model of the rectangular section for $b / h=1$. 


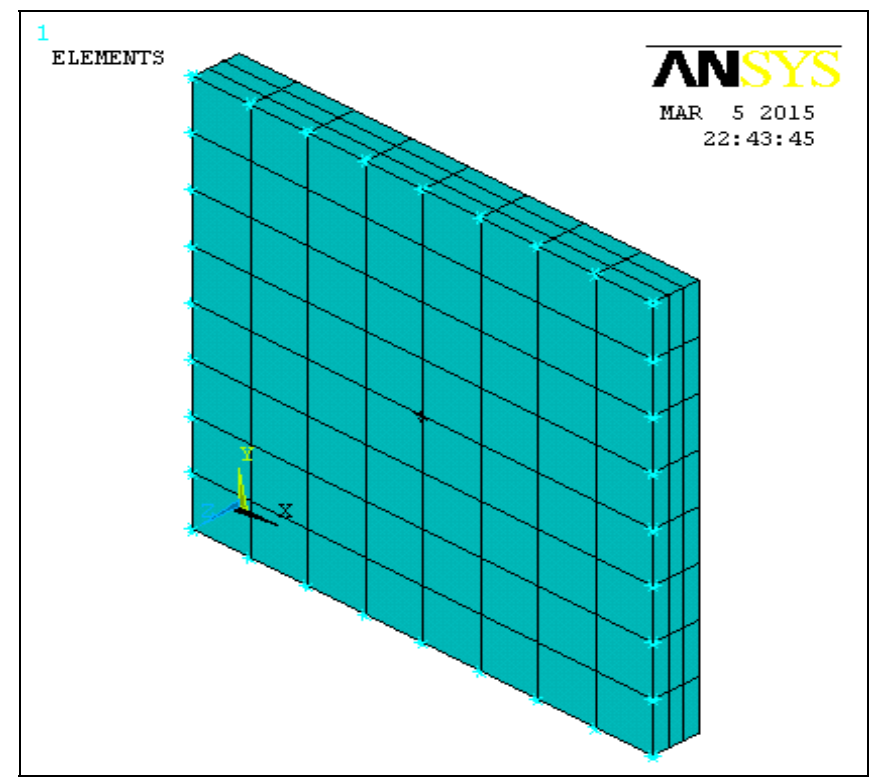

Fig 3: FEM model of Rectangular plate for $b / h=1$

\section{RESULTS \& DISCUSSION}

Figures 4 and 5 show the maximum shear stress and angle of twist for the rectangular section with $\mathrm{b} / \mathrm{h}=1$. The variations in maximum angle of twists and maximum shear stress for different $b / h$ values obtained from ANSYS, Finite Difference Method and analytical equations are shown in tables 2 and 3 respectively.

The magnitudes of maximum shear stress and angle of twist reduced with increase in the ratio $\mathrm{b} / \mathrm{h}$ as seen in tables 2 and 3 . From tables 2 and 3 it can be observed that the percentage variations in the results obtained Finite difference and Ansys are found to be minimal. This may be attributed to the fact that, both methods employ the concept of discretization of the domain.

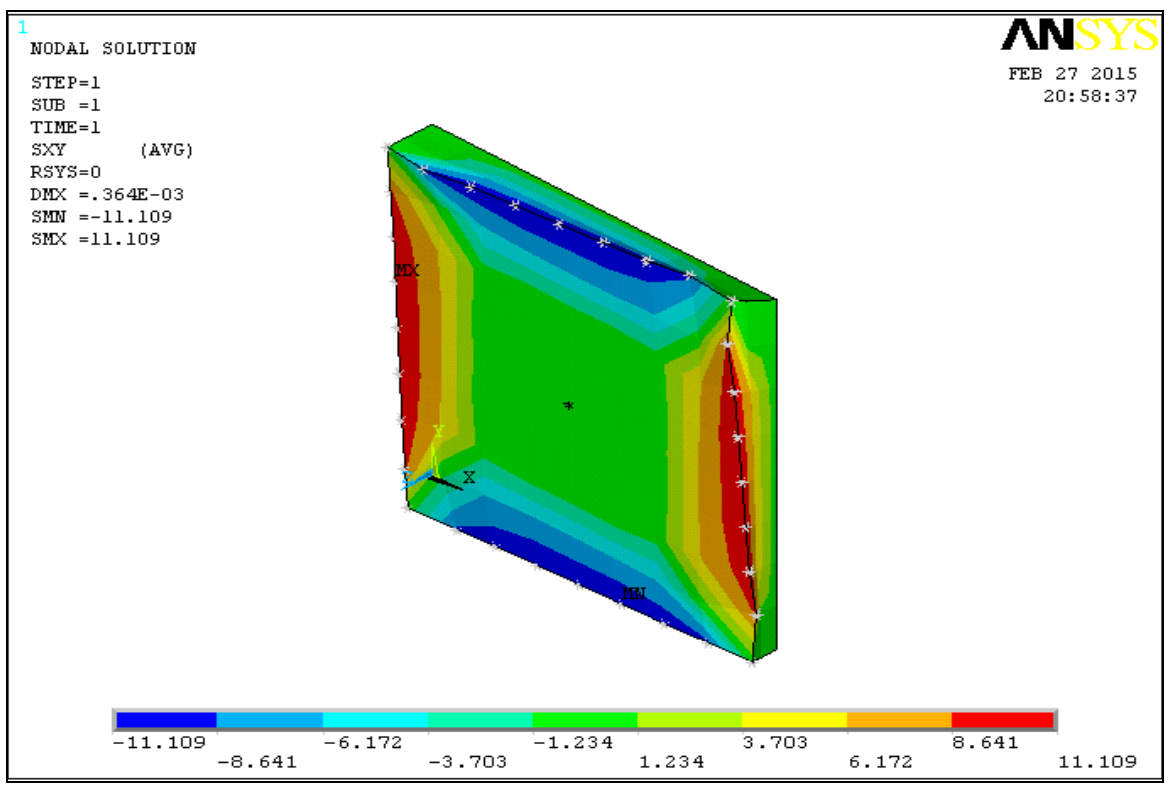

Fig 4: $x y$-shear plot for the rectangular section with $\mathrm{b} / \mathrm{h}=1$ 


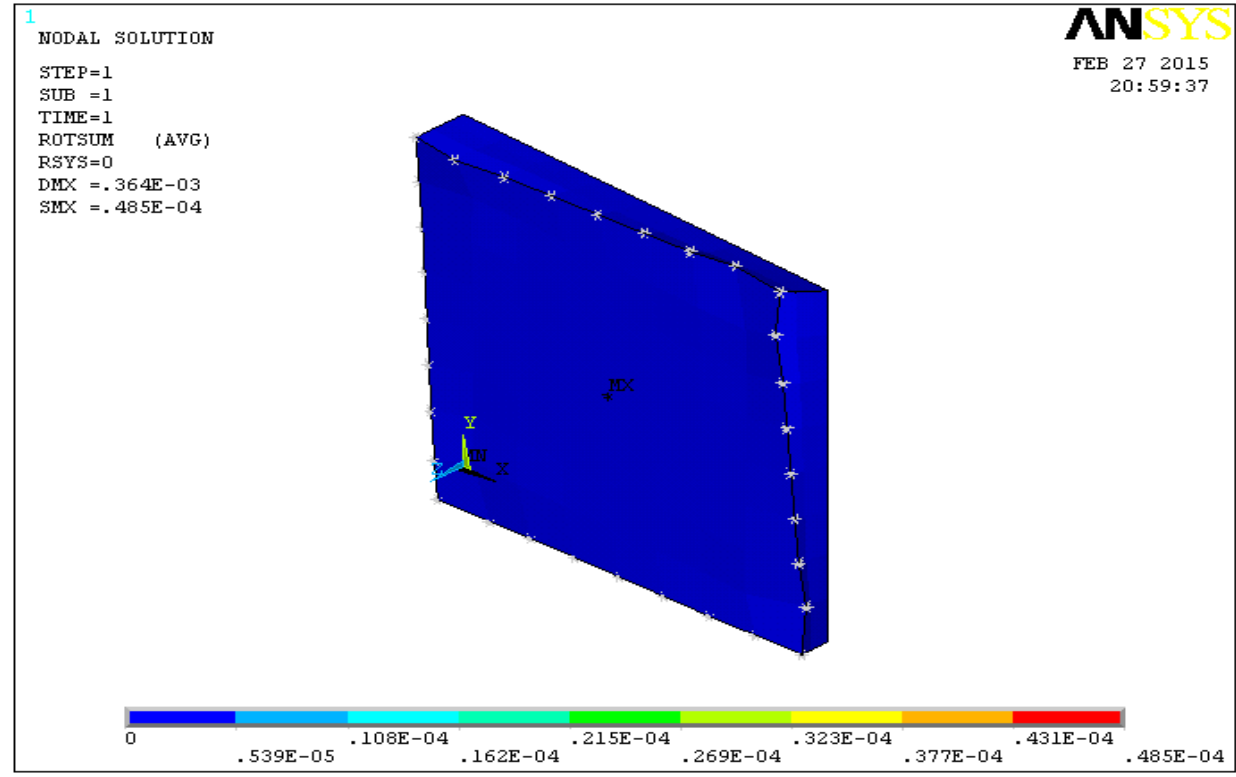

Fig 5: Angle of twist about Z-axis for section with $\mathrm{b} / \mathrm{h}=1$

Table 2: Maximum Shear stress variation for different $b / h$ values

\begin{tabular}{|l|l|l|l|l|l|}
\hline \multicolumn{5}{|c|}{ Maximum Shear Stress in $\mathrm{N} / \mathrm{mm}^{2}$} \\
\hline b/h & 1.0 & 1.5 & 2.0 & 2.5 & 3.0 \\
\hline ANSYS & 11.10 & 7.002 & 4.967 & 3.521 & 2.906 \\
\hline FINITE DIFFERENCE METHOD & 11.45 & 7.342 & 4.993 & 3.648 & 2.997 \\
\hline ANALYTICAL CORRELATIONS & 11.92 & 7.517 & 5.081 & 3.906 & 3.121 \\
\hline
\end{tabular}

Table 3: Maximum variation of angle of twist for different $b / h$ values

\begin{tabular}{|l|l|l|l|l|l|}
\hline \multicolumn{7}{|c|}{ Maximum Angle of twist in radians } \\
\hline b/h & 1.0 & 1.5 & 2.0 & 2.5 & 3.0 \\
\hline ANSYS & $0.48 \mathrm{E}-04$ & $0.12 \mathrm{E}-04$ & $0.063 \mathrm{E}-04$ & $0.0291 \mathrm{E}-04$ & $0.0094 \mathrm{E}-04$ \\
\hline FINITE DIFFERENCE METHOD & $0.427 \mathrm{E}-04$ & $0.109 \mathrm{E}-04$ & $0.060 \mathrm{E}-04$ & $0.033 \mathrm{E}-04$ & $0.0099 \mathrm{E}-04$ \\
\hline ANALYTICAL CORRELATIONS & $0.402 \mathrm{E}-04$ & $0.099 \mathrm{E}-04$ & $0.058 \mathrm{E}-04$ & $0.036 \mathrm{E}-04$ & $0.0101 \mathrm{E}-04$ \\
\hline
\end{tabular}

\section{CONCLUSIONS}

A structural member of rectangular section with different $b / h$ values is analyzed using ANSYS, Finite difference method and Prandtl's closed form solutions for regular non-circular sections. The following conclusions are drawn.

- The accuracy of finite difference method is influenced by grid size S.

- The maximum shear stress values found for three different element sizes i.e. $(10,8$ and 6$)$ were almost identical showing negligible effect of mesh density.

- Instead of second order finite difference formulae, higher order finite difference formulae can also be used for better accuracy and for minimizing error, but the process becomes cumbersome. 
INDEPENDENT JOURNAL OF MANAGEMENT \& PRODUCTION (IJM\&P)

http://www.ijmp.jor.br

v. 6 , n. 3, July - September 2015

ISSN: 2236-269X

DOI: 10.14807/ijmp.v6i3.323

- The concentration of maximum shear stress is at $i=3, j=1$ according to finite difference method and also as observed from Figure 4.

\section{REFERENCES}

BORESI, A. P.; CHONG, K. P. (2010) Elasticity in Engineering Mechanics, $3^{\text {rd }}$ edition, John Wiley and sons, p. 165-219.

BORESI, A. P.; SCHMIDT, R. J. (2014) Advanced Mechanics of materials, $6^{\text {th }}$ edition, Wiley publishers, p. 216-225.

CHATOPADHYAYA, S. (2013) A study of warping in various Non-circular shafts under torsion, $120^{\text {th }}$ ASEE Annual conference, ATLANTA, p. 27-35.

NEWCHEN, C. (1999) The differential quadrature element method irregular element torsion analysis model, Journal of applied mathematical modeling, v. 23, n. 4, p. 309-328.

SINGH, S. (2013) Theory of Elasticity, $4^{\text {th }}$ edition, Khanna Publishers, p. 234-240.

STRIKWERDA, J. C. (2004) Finite different schemes and partial differential equations, $2^{\text {nd }}$ edition, SIAM, P. 12-427.

TÜRKEN, H.; KADIOĞLU, F. N.; ATAOĞLU, Ş. (2002) The Solution of Torsion Problem for the Bars with Irregular Cross Sections by Boundary Element Method, International journal of mechanics and applications, v. 4, n. 2, p.29-49.

UGURAL, A. C.; FENSTER, S. K. (2003) Advanced Mechanics of materials and applied Elasticity, $5^{\text {th }}$ edition, Pearson Education Inc., p. 321-330.

WARD, A. J. B. (1998) The Mathematical Gazette, v. 82, n. 494, p. 215-224. 